

\title{
LA MODÉLICA GESTIÓN DEL CONTADOR DE CRUZADA DE LIMA GONZALO DE LA MAZA
}

\author{
POR .
}

\author{
JoSÉ ANTONıO BENITO RODRÍGUEZ
}

Arequipa (Perú)

\section{Resumen}

Damos a conocer algunas facetas de la gestión administrativa del primer contador de la Bula de Cruzada en Perú, don Gonzalo de la Maza, tal como lo presenta la documentación del Archivo de Simancas. Además de su labor pionera y eficaz en el campo de esta institución, destacamos de su perfil biográfico el haber ofrecido su hogar a santa Rosa de Lima, hasta el punto de ser llamado "padre" por ella.

\section{Abstract}

The exemplary work of the "Contador de Cruzada" of Lima Gonzalo de la Maza

In this work several aspects of the administrative management carried out by Gonzalo de la Maza as the first Accountant of the Bula de Cruzada in Perou are shown, according to the papers in Simancas' Archive. We emphasize his effective work in that institution. Furthermore we point out that he offered his house to saint Rose of Lime, who even called him her "father".

La bulliciosa y extraordinaria vida virreinal de Lima se compone de hombres excepcionales y otros muchos que, a la sombra, vuelcan su profesionalidad sobresaliente a la causa del buen ser de la Corona que les ha enviado y

Missionalia Hispanica Hispania Sacra 48 (\$996) 
que, en última instancia, proyecta como ideal el bien común de los súbditos americanos a través de la humanización y la evangelización. Virreyes como Velasco, prelados como Toribio de Mogrovejo, mujeres como Rosa de Lima impregnan la sociedad virreinal del primer tercio del siglo XII de altas cotas culturales y religiosas. No olvidemos que van a convivir personajes de la talla de Juan Macías, Martín de Porres, Juan del Castillo, santo Toribio, P. Urraca, santa Rosa. Sin embargo, no podemos pensar que son islotes aislados y desconectados del dinamismo social de su tiempo; junto a ellos hay núcleos vitales de personas que constituyen el humus de aquellos o que se convierten en el fruto de su siembra. Es el caso de Gonzalo de la Maza, santanderino enviado a Perú para ponerse al frente de la recién creada Contaduría de Cruzada en el Perú. El tendrá la gracia de hospedar en su misma casa, los últimos años de su vida, a Rosa de Lima, la santa más popular de toda América. Su competencia profesional, iniciada en la Contaduría Mayor de El Escorial, será trascendental en Perú, llenando el primer tercio del siglo XVII con su eficacia. Ello no le impedía, más bien le impulsaba, seguir una vida de militancia cristiana en la que la oración, la lectura espiritual y el ejercicio de la caridad eran lo habitual, convirtiéndole en un contemplativo en la acción, sin esquizofrenias o facetas vitales yuxtapuestas, sino con una coherencia entre su vida interior y exterior que, brotaba, sin duda, de su poderosa energía espiritual en torno a la cual unificaba toda su persona y toda su actividad.

\section{EL TRIBUNAL DE CRUZADA}

La Bula de Cruzada es un documento pontificio que contiene favores espirituales ${ }^{l}$ destinados a quienes -previas disposiciones personales- se comprometían a participar en la lucha contra los infieles, tanto de forma directa (en la guerra) como indirecta (a través de una limosna).

En un primer momento, nos encontramos con la institución de la Bula en Indias, pero como expansión espontánea, lógica y natural, desde la Península, pues acuden personas a ultramar todavía sin crearse tribunales o instituciones

1 Destacan este marcado contenido espiritual las obras de J. de ARGOMANAS: Tratado muy provechoso para todo fiel cristiano que quisiese saber el efecto de las indulgencias y perdones. Sevilla, 1548, Biblioteca Nacional de Madrid, R. 12971. M.RodríguEz: Explicación de la Bula de Santa Cruzada, Salamanca, 1594 (Biblioteca Nacional de Madrid R 35351; Biblioteca de PP.Filipinos, SI 225I, Valladolid). M. DE TORRECiLlA: Apología sobre la Bula de la Cruzada y sus privilegios, gracias $e$ indulgencias..., 1699. Biblioteca de Santa Cruz de Valladolid, Impreso 4660; P.Pedro MoNTENeGro S.I.: Sermón manuscrito de Bula de Samta Cruzada predicado en Granada en 1658 en presencia del arzobispo, los dos cabildos y tribunal de Santa Cruzada Biblioteca Nacional de Madrid, Códice 1]319-29.

Missionalia Hispanica Hispania Sacra 48 (1996) 
y se arrienda la recaudación de la limosna por asiento a personas concretas, como Hernando Vázquez o Francisco de Medina. En 1573, con motivo de la concesión de Gregorio XIII, se da un paso decisivo, que da lugar al primer asiento o contrato con los primeros tesoreros generales, Díaz Becerril, J.A. Medina y F. Martínez. Ese mismo año se otorga licencia para pasar a Indias a treinta y seis personas, durante seis años, en la administración de la Bula. Disponemos también de bulas pontificias, reales cédulas, instrucciones y ordenanzas, cuentas, impresiones, etc. Así, hay una real cédula de este mismo año comunicando al virtey de Perú la concesión de Cruzada por Gregorio XIII, y otra ordenando al Virrey Toledo "dé favor y calor" para que la Bula sea recibida con la decencia requerida ${ }^{2}$.

La ley primera del apartado dedicado a Cruzada de la Recopilación de Leyes de Indias manda fundar el Tribunal de Cruzada:

"Por cuanto para la buena administración de la bula, que se predica y publica en las provincias de nuestras Indias ha parecido convenir, que en los lugares principales haya un Tribunal formado, para que en él nuestros súbditos y vasallos tengan mejor, más cómodo y cercano recurso donde acudir en apelación con las causas que hubiere y se sentenciaren por los Jueces Subdelegados particulares de aque! distrito y jurisdicción?".

M. Mendiburu nos dice que el Tribunal de Perú fue fundado por el virrey Toledo ${ }^{4}$ pero que "se organizó de nuevo en dicho año (1604) el Tribunal de la Santa Cruzada, siendo comisario delegado el célebre arcediano de la catedral de Lima y doctor de la Universidad de san Marcos D.Juan Velázquez de Obando"s. De esta fuente documental parece beber D. Angulo, quien nos recuerda que el Tribunal funcionaba en la Calle de Santo Toribio, casa de las bulas ${ }^{6}$.

De la lectura de las crónicas como la de Fr.Diego de Córdoba Salinas Teatro de la Santa Iglesia Metropolitana de los Reyes se desprende que la fundación primera sería la de Lima, en 1603-16047:

"El [Tribunai]] de la Santa Cruzada se fund 6 el año de 1603 para todas las cosas de la expedición de la bula y privilegios de ella. Está el Tribunal en casa del Comisario $\mathrm{Ge}$ neral, que de ordinario es una Dignidad o Canónigo de la Santa Iglesia Catedral de Li-

2 D. DE EnCinas: Cedulario Indiano. Edición de García Gallo, Madrid, 1945. pp. 234-235.

3 RECOPILACIÓN DE LEYES de lOS REINOS DE LAS INDIAS. Facsímil de J. F. PARedes, Cuitura Hispánica, Madrid, 1973. J, XX, L.1.

4 M. MEndibuRu: Diccionario histórico-biográfico del Perí. 11 tomos. Lima, 1934. Tomo X.

5 Mendiburu, M.: Diccionario histórico-biografico del Perí. 11 tomos. Lima, 1934. XI, p.278.

- D.ANGulo: "El Cedulario Arzobispal de la Arquidiocesis de Lima". Revista del Archivo Nacional del Perú. III, Lima, 1925. pp 45-46, nota $n^{\circ} 5$.

7 Fr.Diego De CóRDoba Salinas, en Teatro de la Santa Iglesia Metropolitana de los Reyes (1650). p. 12 . 
ma, con mil pesos ensayados de Renta, consignados en la expedición de la bula. Tiene $u$ asesor que es siempre es oidor de la Real Audiencia por cédula de Su Majestad y con 250 pesos de salario; un contador con 3.000 pesos ensayados y todos estos salarios consignados en la expedición de la Bula. Tiene otros muchos oficiales y ministros menores con sus salarios librados en gastos de Estrados. El primer comisario de Cruzada que tuvo este Tribunal fue el Doctor D.Juan Velázquez, Arcediano de la Iglesia de Lima"8.

Con motivo de la real cédula de 1609 se irían creando tribunales en México, Nueva Granada... En la Carta de Gonzalo de la Maza (Lima 30 de marzo de 1610) se nos habla de la real cédula de 16 de mayo de 1609 enviada al virrey Montesclaros en la que se manda que donde hubiese Audiencias Reales se fundasen Tribunales de Cruzada ${ }^{9}$, que comprendiesen los distritos de las audiencias y se formasen de los subdelegados que nombrase el Comisario General y del oidor más antiguo y fiscal de cada una de ellas y del Oficial Real más antiguo, exceptuando las ciudades de Los Reyes y México en donde estaban formados los dichos tribunales de personas que lo serían. De la misma fecha se nombró como Comisario General a D.Pedro Muñiz. Éste, enseguida, excomulgó a Juan Velázquez, quien a su vez le excomulgó por haberlo hecho sin tomar posesión.

\section{LA FUNCIÓN DE LOS CONTADORES}

En España llevaban los libros de la hacienda de las Tres Gracias, subsidio, cruzada y excusado. En las Contadurías se ejecutaban cuantos despachos de oficio se ofrecían, relaciones, ajustamientos, informes que pedía el Consejo, pleitos fiscales, cuentas, despacho de la publicación de la Bula para Indias, nóminas, libranzas de mostrencos para rescates, sus justificaciones, libranzas al Tesorero, reuniéndose semanalmente para ver y conferir sus libros.

De acuerdo con lo establecido en las Leyes de Indias, el contador del tribunal de Cruzada era el más antiguo de los Oficiales Reales, excepto en las ciudades de México y Lima, donde se nombraban contadores particulares. Tenían voz y voto en materia hacendística y, por supuesto, podían nombrar personas que con títulos suyos ejercieran como tenientes con sus mismas prerrogativas, cubriendo las plazas de contadores y consejeros. Debido a que el virrey Esqui-

\footnotetext{
- Coincide Francisco López de Caravantes en su Noticia General del Petú Discurso IV, n* 133. 142: El Tribunal de la Santa Cruzada que se fundo el año de 1603 para todas las cosas de la expedición de la Santa Bula y privilegios de ella. BAE 293, Madrid 1986. pp 41-42.

\& Coincide Francisco Lopez de Caravantes en su Noticia General del Perú Discurso IV, n 133 142: El Tribunal de la Sania Cruzada que se fundo el año de 1603 para todar las cosas de la expedición de la Santa Bula y privilegios de ella. BAE 293, Madrid 1986. pp 41-42.
} 
lache señaló 10 pesos ensayados de salario cada día al entonces Contador Alonso de Pastrana ${ }^{10}$, al monarca Felipe III le pareció excesivo, por lo que se dispuso que se le gratificase por cada trabajo y no por días agase por no se le señalase salario por días y que acabadas las cuentas y considerada la ocupación por entero y no por días, tal como se observaba en la Contaduría mayor de Cuentas ${ }^{11 "}$.

Con el título de "contador" se designaba a un gran número de funcionarios de las más diversas categorías y escalas. El que podríamos denominar contador común o general es el titulado así en la legislación y del que hablamos al comenzar el capítulo. Existía en todo tribunal de Cruzada como cargo estable y necesario para el funcionamiento de este organismo básico de la institución de la Bula; su puesto lo cubría generalmente el Oficial Real que desempeñaba este mismo oficio de contador en la Contaduría Mayor de Cuentas.

Los contadores mayores se nombraban para los tribunales más destacados, Lima y México en primer lugar y Nueva Granada, Guatemala, La Plata en menor medida y sólo en algunos períodos de mayor intensidad laboral. A veces le tocaba ejercer simultáneamente como tesorero y contador por no haber encontrado nadie que hubiese arrendado la tesorería, como le sucedió con el tesorero-contador Hernando Arias Torero hacia 1586 en Santa $\mathrm{Fe}^{12}$. Junto al contador mayor estaba el contador-notario, puesto que desempeñaron los contadores mayores Nicolás Garzón Melgarejo en 1662 en Nueva Granada ${ }^{13}$ y Francisco Barón de Berrueza hacia 1731 en Guatemala ${ }^{14}$.

A veces se nombraba temporalmente con dicho empleo a una persona para un caso específico, como las visitas a los Tribunales. Entre otros muchos, cumplieron con esta tarea Francisco García Collantes y Juan Francisco García Montes $^{15}$, que les tocó revisar las 114 cuentas fiscalizadas por el Obispo de Cuzco Alonso de Ocón en los Tribunal de Perúl6, hacia 1650. Este es el caso también de Antonio Espínola y Pineda y Juan Rodríguez Redondo que ejercieron de contadores durante la visita realizada por el obispo de Michoacán, Marcos Ramírez del Prado, a los tribunales de Nueva España entre 1646-

10 Real Cédula con la Orden de establecer Tribunales donde hubjese audiencias Indias 1609: M.J. Ayala: Diccionario de Gobierno y Legislación de Indias. Estudio de M.M.del Vas Mingo. Cultura Hispánica, Madrid, 1989.

" M.J. DE AYALA Notas a la Recopilación de Indias. Estudio de J.Manzano, Culturo Hispánica, Madrid, 1945, p.378.

12 Recopilación...[3]. Libro I, Título 20, Ley I.

13 AGI (Archivo General de Indias), Contratación, 1301.

14 AHN (Arcijivo Histórico Nacional), Consejos, 51688.1.

is AGS (Archivo General de Simancas), CCI (Comisaría General de Cruzada, "Indias"), 570.

16 AGS, CCI, 561. 
$1648^{17}$; Juan Rodríguez Redondo recibirá 600 ducados y 200 pesos como ayuda de costa para su viaje ${ }^{18}$.

Lógicamente, en tan largo período fueron muchos los contadores que ejercieron el cargo; pero, sin duda alguna, entre todos ellos, destaca la familia Maza-Zabala.

\section{LOS MAZA Y ZABALA: UNA FAMILIA DE CONTADORES}

Habitualmente, los elegidos para este cargo eran figuras relevantes. Este fue el caso de Gonzalo de la Maza, que traspasará el título a su yerno Andrés Zabala $^{19}$, perpetuándolo en la familia durante todo el período en que estuvo vigente la institución. La explicación de esta perpetuación del cargo de contador del Tribunal de Cruzada de Lima en la familia se debió a la vinculación del empleo por mayorazgo efectuada en $1645^{20}$. No se trata en este caso de un "mayorazgo corto"21, tan frecuente en América por constituirse sin licencia real sobre el quinto y mejora del tercio de los bienes de libre disposición por personas de mediano caudal, sino de un mayorazgo fundado con facultad real que vinculó a los bienes familiares un empleo de notable categoría y bien remunerado, lo que tampoco constituye una excepción en América, pues también se vincularon por mayorazgo cargos como los de factor de la Real Hacienda, adelantado de Filipinas, etc.

17 AGS, CCI, 556.

18 AGS, CCI, 556 y 578 .

19 Andrés de Zabala se casó con una de fns hijas de don Gonzalo de la Maza, Micnela. La otra, Andrea, desposó con el capitán Alonso Bravo, contador mayor del Tribunal de Cuentas. Vid. M. MEndiburu: Diccionario histórico-biográfico del Perti. Lima, 1934. Tomo 3, pp.126-127.

20 AGS, CCI, 576. Su cabecera es la siguiente: " Cláusula de fundación. En la ciudad de los Reyes del Piru, en tres días de junio de mil y seiscientos y quarenta y cinco uños. Ytem, declaro que yo y la dicha doña Micaela de la Maza y Usátegui, de conformidad, hicimos, instituimos y fundamos un vínculo y mayorazgo con facultad real en cabeza del dicho don Martín de Zavala y Usátegui, nuestro hijo; para lo cual, le mejoramos en el dicho remanente de quinto de nuestros bienes y así ganamos para este vínculo y mejora el oficio de Contador de Su Majestad del Tribunal de la Cruzada de este Reino; y estas casas en que vivo y las tiendas accesorias a ellas en que no se comprebende la casa que tengo alquilada a $D^{\mathrm{a}}$ Beatriz de Paredes, viuda del capitán Francisco López Gutiérrez, que ésta queda libre mía y apruebo la dicha mejora y vínculo y declaro que demás de los dichos bienes vinculados tengo de bienes libres en Reales y joyas, esclavos y alhajas de casa y otros bienes con lo que me deben diferentes personas hasta en cantidad de 170.000 patacones más o menos los que se hallaren conforme al inventario que por mi fin y muerte mando se haga."

21 Vid. L. MuAares: "La sociedad", Historia General de España y América. S.XVII, Rialp, Madrid, 1988.

Missionalia Hispanica

Hispania Sacra 48 (1996) 
A la muerte de don Andrés sirvió la Contaduría su hijo D. Martín de Zabala y de la Maza, Caballero de Santiago, casado con Teresa Villela y Esquivel, hija del oidor de Lima, Andrés de Villela. Le sucedió Francisco de Zabala y Villela, de la orden de Calatrava, casado con $D^{2}$ Rosa de Esquivel y Navia, nacida en el Cuzco. A su muerte, en 1733, lo heredó el capitán José de Zabala y Esquivel, nacido en 1690, quien casó con $D^{\mathrm{a}}$ Ángela Vásquez de Velasco. Desde luego no fue fácil mantener la vinculación del empleo. Según la documentación, hubo distintas tentativas para romper este vínculo, la más importante de las cuales, sin duda, fue la acometida sin éxito por el fiscal de Lima contra José Zabala Esquivel. Un Informe realizado el 13 de abril de 1739 como consecuencia del memorial elevado por dicho fiscal en solicitud de que se le guardasen las preeminencias, exenciones y precedencia en el tribunal, como le estaba concedido por sus títulos, desarrolla toda la fundamentación jurídica en que se apoyaba el título de contador.

A José Zabala le sucedió su hijo el capitán Tadeo Martín de Zavala Vásquez de Velasco, que casó con $D^{a}$ Mariana Pardo de Figueroa y Esquivel, marquesa de San Lorenzo de Valle-Umbroso, nacida en el Cuzco. A su muerte, lo heredó el primogénito D.Pedro Nolasco de Zabala, marqués de Valleumbroso ${ }^{22}$, último contador general de Cruzada. Nació en el Cuzco en 1761 y se casó con $D^{a}$ Ana Micaela Bravo del Rivero y Zavala, hija del oidor D.Pedro Bravo del Rivero y Correa, consejero honorario que falleció en 1787.

Un año antes, el empleo de contador, junto con los restantes de Cruzada, se habían extinguido por resolución de 19 de septiembre de 1786, de acuerdo con el artículo 149 de la Instrucción de Intendentes, quedando el ramo incorporado a la Corona. El Rey indemnizó la propiedad de los empleos vinculados; el de contador fue avaluado en 80.000 pesos y por este principal se pagaron al último Marqués de Valle-Umbroso, D.Pedro José de Zabala, 4.000 pesos anuales de interés, que percibió hasta 1820 en virtud de real orden de 2 de julio de 1802. Después los reclamó en España, reconociéndole, en 1826, el derecho a esa renta ${ }^{23}$.

22 Biblioteca de la Real Academia de la Historia, Colección Mata Linares. IV, 7869, T.CX ff 696-700. El Intendente Mata Linares, buen conocedor del Cuzco por su estancia en el virreinato, nos da cuenta en su colección de un tal Francisco Parrilla, Marqués de Valleumbroso, administrador general de las rentas del Cuzco. El 16.2 .1784 presento cuenta jurada de lo correspondiente al ramo y a la publicación de la primera predicación de la $19^{\circ}$ concesión, de 1781-1782, con un balance de 107.337 bulas y un valor de 31.522 pesos.

${ }^{23}$ M. MEndiburu: Diccionario... [143]. p.374. 


\section{UN CÁNTABRO EN LA HACIENDA CASTELLANA}

Gonzalo de la Maza Sánchez nació en Ogarrio ${ }^{24}$ o Ugarro, valle de Ruesga, pueblo que perteneció a la provincia de Burgos y que hoy, tras la división administrativa, corresponde a Santander, hacia 1560 . Sabemos por su testamento que ésta fue la patria de sus padres cuyos nombres fueron Gonzalo Pérez de la Massa y Catalina Sánchez de la Hermosa, y que tuvo una única hermana, Juana de la Maza ${ }^{25}$. Un documento del Archivo de la Chancillería de Valladolid ${ }^{26}$, nos informa de la solicitud que hiciese su padre al "Concejo de hombres buenos y empadronadores del Valle de Ruesga" para que quitasen de los padrones donde se le tienen asentado por hidalgo y se le repartan los pechos correspondientes, en junio de 1573.

Sirvió al Rey como funcionario de las "ordenanzas y disposición de las cuentas más de doce años y haber servido en el oficio de contador de resultas mucho tiempo y en la contaduría mayor de contador ordenador de ellas y antes en los libros, ejercicio y papeles de los gastos de la fábrica de San Lorenzo el Real" ${ }^{27}$, en cuyos negocios acreditó sobrada inteligencia.

Por real cédula de $12.10 .1598^{28}$ se le autoriza que pase a Indias con su mujer, $D^{a}$ María de Usátegui y Ribera, madrileña, bautizada en la parroquia de San Miguel el 30 de diciembre de $1566^{29}$. Por los datos que nos facilita la Casa de Contratación de Sevilla, en el momento de los preparativos para formalizar su pasaje, sabemos que su esposa tendría 32 años, "blanca, de buen cuerpo". Le acompañan sus dos hijos: Diego, el mayor, que tendría 12 años y el menor, Jerónimo, con 10 años ${ }^{30}$. De los hijos no tenemos más datos por lo que presumimos que morirían en el viaje o al llegar a Perú. En su testamento sólo cita a dos hijas.

Junto a su mujer e hijos, se le permite pasar a cuatro oficiales que le ayuden a su oficio y dos criados en los galeones de la flota del General Marcos de Aramburu. Por hallarse en "mucha necesidad", no puede pagar los fletes al contados, solicitando poder pagarlos desde Cartagena de Indias que es el destino de la flota ${ }^{31}$, en caso de que no se pueda hacer efectivo deja como fiador a Luis de Paz, vecino de Sevilla. Por los Libros de Pasajeros del Archivo de

\footnotetext{
${ }^{24}$ MendiBuru, M.: Diccionario... VII, p.258-9.

25 Testamento de don Gonzalo de la Maza, Archivo Histórico Ruva-AgÜERo/ M-1-384, Linta.

${ }^{26}$ Sección "Pleitos de hidalguía", expediente 633-42.

27 AGS, CCI, 576. Pardo, 1-2-1625.

28 AGI, Indiferente, 2865.1.

${ }^{29}$ G. LOHMANN VILLENA: Los americanos en las órdenes nobiliarias. CSIC, Madrid, 1993. 2 tomos.

30 A.G.I., PASAJEROS L.8, E-109.

3) AGI, Contratación, 5262 B, N, 33. 
Indias conocemos que con D. Gonzalo de la Maza pasaron Catalina de Rada y Alonso Enríquez, como criados, y, Juan Ochoa de Valda y Zárate, Diego de Alviz, Juan Sebastián Martínez, como oficiales ${ }^{32}$. Además, le autorizan a llevar consigo un esclavo negro, 4 espadas y 4 dagas, 400 pesos de joyas en oro.

La razón de su partida era el ordenar las cuentas de la Contaduría de Cruzada de Lima en completo desorden tras el asiento de los tesoreros Miguel Sánchez de la Parra y Beltrán Aparicio ${ }^{33}$.

En Madrid, 12 de enero de 1600 , se le otorga título y comisión a Gonzalo de la Maza como contador de Cruzada en Perú; con un salario anual de 2000 pesos anuales ${ }^{34}$ estipulados desde que se hubiese hecho a la vela en el puerto đe Sanlúcar o Cádiz y cuyo pago deberían los Oficiales Reales de Lima ${ }^{35}$. A través de otras disposiciones se concreta su misión; así, el 25 de enero del mismo año, se le designa como contador para que, con dependencia del doctor Juan Velázquez, Comisario de Cruzada en Perú, vea cómo se han tomado las cuentas de las predicaciones por parte de los Oficiales Reales. Se le comunica a la Audiencia de La Plata, constatando desde Madrid que el aumento de la Hacienda de Nueva España es un hecho "después de que la subdelegación se rige por persona particular ${ }^{36 "}$. Se puede ver esto también en la Provisión Real enviada desde Madrid, el 5 de enero de 1600:

"habiéndose consultado las buenas partes, letras y prudencia del Doctor Don Juan Velázquez, arcediano de la Santa Iglesia de esa ciudad, don Juan de Zúñiga, electo obispo de Cartagena, del mi consejo y del de la Santa y General Inquisición, comisario apostólico general que al presente es de la dicha Santa Cruzada, le ha dado su poder y comisión para que sea su subdelegado general, así en ese dicho arzobispado de Los Reyes como en los demás partidos de esas provincias del Perú y tierra firme; y por parecer que conviene a mi servicio y a la buena cuenta y razón que se debe tener de lo procedido de la dicha Crizada para lo gastar y distribuir en los efectos para que ha sido concedido, y que las cuentas de ello se tomen por el estilo y forma que en mi contaduría mayor de las de Castilla se toman de lo procedido en estos reinos, he nombrado al contador Gonzalo de la Maza y dádole poder y comisión para que vaya a esas provincias, y con dependencia del dicho doctor Don Juan Velázquez vea como y de la manera que se han tomado por mis Oficiales Reales las cuentas que de lo procedido de las predicaciones que de la dicha Cruzada se han hecho en ellas les han dado los tesoreros generales y particulares que han sido de ella y sepa el paradero y asista con los dichos oficiales al tomar y fenecer de las que no lo estuvieren ${ }^{37 "}$.

\footnotetext{
32 AGI, Contratación, 5262.

3 AGS, CCI, 576. Pardo, 1-2-1625.

${ }^{34}$ AGS, CCI, 586.

35 AGI, I, 2865.l. Madrid, 16 de febrero de 1600.

36 Biblioteca Nacional de Madrid, Manuscrito 2927, 100, f.302-3.

${ }^{37}$ Colección de documentos inéditos relativos al descubrimiento, conquista y organización de las antiguas posesiones de América y Oceanía. Madrid, 1864-1884. I,19, pp.107-109.
} 
También al virrey don Luis de Velasco se le envía una real cédula para que dé su favor y ayuda a los dos ${ }^{38}$.

\section{MISIÓN DEL CONTADOR GONZALO DE LA MAZA}

Conocemos detalladamente su misión gracias a la comisión enviada al Comisario Subdelegado de Cruzada en Perú, el Arcediano Juan Velázquez, y que fue dada en Madrid el 25 de enero de 1600. En primer lugar, le comunica la elección de Gonzalo de la Maza. A continuación Ie indica que nada más recibir esta carta y las instrucciones del Comisario General de Cruzada y su Consejo lo haga conocer por todos los partidos y provincias recaudando todo lo que hubiese pendiente. Para ello se le faculta con el poder de "nombrar y elegir las personas que fueren menester con salarios y entretenimientos moderados de quienes se tomara la seguridad necesaria y para que con vara alta de mi justicia ejecuten vuestras comisiones y mandamientos que a los que fueren les doy poder comisión cumplida cual al caso conviene". Manda que los Oficiales Reales muestren sus libros de cuentas de las cuentas de las predicaciones que han tomado y tomaran a los tesoreros y oficiales de Cruzada así como el paradero de las bulas y los dineros. De todo se dará cumplida información al Consejo de Cruzada. Por su parte, el Rey se responsabiliza de mandar al virrey del Perú y a los presidentes y oidores, alcaldes de corte, gobernadores, corregidores, alcaldes mayores y ordinarios, justicias para que le den todo favor y ayuda. Por último le recuerda el fuero privativo que tiene como subdelegado del Comisario, tanto en la jurisdicción apostólica dependiente del Papa como en la real. Por ello manda que "os guarden y hagan guardar las honras, preeminencias, libertades y exenciones que se suelen y acostumbran guardar a las personas que sirven en semejante ministerio ${ }^{39 "}$.

Por una Instrucción General de 43 puntos para J. Velázquez y Gonzalo de la Maza, de 8 de febrero de 1600 , se especifica la misión ${ }^{40}$, que ya había sido regulada perfectamente antes de su partida de España mediante una instrucción titulada "Modo y manera de tomar las cuentas y lugar por el contador $\mathrm{G}$. de la Maza" que dio a conocer el virrey el 20 de diciembre de $1601^{14}$. En ellas se le ordenaba efectuarla al estilo de la Contaduría Mayor de Castilla, donde

\footnotetext{
${ }^{38}$ Colección de doctmentos inéditos relativos al descubrimiento, conquista y organización de las antiguas posesiones de Anérica y Oceanía. Madrid, 1864-1884. I,19, pp.107-109. Dada en Madid, el 25 de enero de 1600.

39 AGS, CCI, 586.

40. AGS, CCI, 573.

4) AGS, CCl, 573 .
} 
había servido desde 1577 hasta su marcha al Perú en $1600^{42}$. Lo hace en unión de los Oficiales Reales, oidor y fiscal. Además de las cuentas ordinarias de las predicaciones, se le encomendaba la tarea de revisar los finiquitos de la primera concesión. En todo ello, trabajó con tal empeño que consiguió la revisión de las del Nuevo Reino de Granada, recuperando más de 200.000 ducados de alcances de cuentas desde 1574, más otros 75.000 ducados de fraudes. A su vez, el virrey Marqués de Guadalcázar y el visitador Juan Gutiérrez Flores le dieron comisión para visitar el Tribunal de Contaduría Mayor donde se quebrantó su salud y economía con tan buenos servicios a la Real Hacienda que dobló los ingresos. El Consejo de Cruzada, tan acostumbrado a dictar sentencias y promulgar ordenanzas que enderezasen la Hacienda en las lejanas Indias, no dudó en aplaudir su gestión con generosas palabras ${ }^{43}$. Además, y con objeto de presentarse con mayor autoridad en todas sus actividades, al igual que se hacía con todos los Oficiales Reales se le concede voz y voto en el Ayuntamiento de Lima ${ }^{44}$.

\section{AVATARES DE UN VIAJE}

En carta dirigida al Rey, el 30 de junio de 1600 , desde Portobelo, da cuenta de los avatares del viaje y su llegada a tierra, cómo se embarcó en el puerto de Bonanza a 8 de abril, el día siguiente se dio a la vela y llegó a Cartagena el 23 de mayo donde se presentó ante el obispo y gobernador para dar cuenta de su misión y dejar asentada la segunda predicación; en el plazo de 22 días que duró su estancia se tomó asiento con Cristóbal Vélez, que ya había sido tesorero en Cartagena y Santa Marta. Aprovechó para la revisión de cuentas pasadas y de las del primer asiento que fueron a cargo de Diego Díaz Becerril y consortes. Resultó de alcance de los dichos partidos 1723 p, intentando subsa-

42 AGS, CCI, 573. Gonzalo de la Maza fue a Pcrú en 1600. Comenzó a servir al Rey en 1577 en la Contaduría Mayor de Castilla. Según él, la Bula de Cruzada se inició en Indias en 1574. Por Real Cédula de 1636 (AGS, CCI, 572) se ordenó al Virrey librar 1500 pesos a María de Uzítegui, viuda del Contador, como ayứa de costa, después de haber pagado 75 pesos por la media annata de 20.400 pesos de plata. Gonzalo de la Maza dejó asentada la administración de suerte que creció en su tiempo el doble de lo que antes valía, y la entereza y rectitud con que procedió y gastos que hizo en largos viajes fue causa de que su mujer quedase con 14.000 pesos de deuda. Madrid 5.9.163!.

43. AGS, CCI, 573. El Consejo de Cruzada dirá que "habrá poco que advertir, pues la satísfacción con que se queda del cuidado y diligencia con que ustedes proceden. en sus oficios asegura el buen gobierno y aumento de la Santa Cruzada como se va viendo por experiencia". Se valora especialmente su gestión como contador, la acertada visitn al Cuzco, Charcas y Quito; la comprobación de los alcances de Miguel Sánchez de la Parra y Juan Beltrán. Subraya que todos los informes de la carta del Contador vienen con la "forma y curiosidad que siempre suele".

44 AGS, CCI, 573. 
nar las deficiencias de la administración de los tesoreros generales Miguel Sánchez de la Parra y muerte de Juan Beltrán de Aparicio, encontrando sin remitir 2917 pesos que se habían gastado en la galera de Cartagena por haber faltado el situado de ella tal y como habían autorizado el obispo, gobernador y el doctor Antonio González; del Nuevo Reino habían bajado a Cartagena 4.700 pesos de oro a cuenta de lo que debía Luis de Salas Covides lo que ha venido aquí en esta ocasión son 9137 pesos de Potosí y de Lima 1354 pesos de buen oro y 15300 pesos ensayados por cuenta de la sexta predicación y lo demás restante por la cuarta y quinta del cargo de Juan Beltrán Aparicio en que entran 2.000 pesos del cargo de Miguel Sánchez de la Parra. A Portobelo llegó el 19 de junio, pero "por falta de salud no pudo pasar de él ni llegar a Panamá".

Sorprende la capacidad de trabajo del Contador y la rapidez de adaptación a su labor, pues apenas ha tomado contacto con la nueva realidad indiana y ya sugiere al Rey iniciativas para mejorar la administración de la bula. Así, de la revisión de las cuentas de Cartagena observó un gasto grande en cada predicación debido al empaquetado y envío de las bulas al Nuevo Reino y a Popayán, gastando más de 600 pesos por cada predicación. Se lo expuso al obispo y gobernador y otras personas de experiencia acogiendo la sugerencia de que a partir de ese momento enviasen las bulas por el Río Grande en fragatas y canoas como va toda la contratación con lo que se ahorrarían unos 300 pesos por lo menos en cada predicación. Termina la carta con un ofrecimiento y un deseo: " Lo que más deseo de presente es tener salud para poder salir de tierra donde hay tan poca y ocuparla toda en el servicio de Vuestra Majestad cuya católica y Real persona Nuestro Señor guarde muy largos años como la cristiandad lo ha menester. De Portobelo, 30 de junio de $1600^{45 "}$.

En previsión de la lógica demora por el habitual azoroso viaje y estas circunstancias narradas de incidentes y faltas de salud, en Perú se tomó asiento en Lima, cinco de agosto de 1600, con Francisco Cano de Nebrija ${ }^{46}$ que hizo las veces de contador interino mientras llegaba don Gonzalo. El 15 de septiembre de 1600, desde Lima, J.Velázquez le comunica al Comisario General no haber recibido noticias de la llegada del Contador $^{47}$.

\footnotetext{
45 AGS, CCI, 573.

46 AGS, CCI, 573.

47 AGS, CCI, 586.
}

Missionalia Hispanica Hispania Sacra 48 (1996) 


\section{LlEGADA A PERÚ: "COMO UN CARACOL CON LA CASA A CUESTAS"}

Tres meses después, el 7 de octubre de 1600, vuelve a escribir desde Panamá $^{48}$. La falta de salud persiste y debe detenerse en Portobelo hasta el 24 de julio. Allí debe dejar enferma a su mujer y mueren dos oficiales de los cuatro que llevaba. El nueve de agosto le avisaron los oficiales reales de Cartagena cómo las bulas que se enviaban al Nuevo Reino de Popayán y Venezuela las habían robado corsarios ${ }^{49}$ a la entrada del Río Grande en una fragata. Al llegar a Panamá buscó administrador en Luis lbâñ̃ez de Laguna, factor, familiar del presidente del Consejo Indias, señalándole de salario la octava parte de lo que procediese. Nos cuenta que se hizo la publicación y recibimiento con la máxima solemnidad. A pesar de ello nadie quiso hacerse con la tesorería. G. de la Maza sugiere que se le honrase con algo como darle voz y voto en cabildo "habiéndolo comunicado con personas desinteresadas y celosas del servicio de Dios y de Vuestra Majestad no se halla inconveniente". Indica la causa de sus sugerencias: "El celo que tengo al bien de este negocio y servicio de Vuestra Magestad me atrae estos pensamientos. Vuestra Magestad proveerá en todo lo que más convenga a su real servicio".

A continuación procura "sacar en limpio lo procedido en este reino", sin conseguirlo, pues no encuentra documentación alguna sobre las pasadas predicaciones. Lo único que sabe es que hasta el momento las predicaciones se hicieron en todos los lugares del reino, que eran seis de españoles, tres de indios dos o tres de negros. Llegó incluso a obtener datos precisos acerca de las bulas libradas pero no de las que sobraron y se consumieron. Anota las dificultades encontradas en su penosa tarea de revisar y subsanar las cuentas:

\footnotetext{
"En dondequiera son malquistos los hombres que introducen novedades y más en las Indias y así lo voy siendo particularmente con Oficiales Reales por cuya mano estas cosas han corrido y no con la puntualidad que a buena cuenta y razón se debe y procuro en todo y con la suavidad templanza y buenos medios que más parece convenir pero en resolución tomo cuentas y procuro cobrar lo que se debe por las vías que digo y nunca los que ejercen semejantes oficios fueron bien recibidos ${ }^{\text {sin" }}$.
}

Desde Panamá el 20 de noviembre de 1600 , Cipriano Fernández de Cea, Subdelegado de Cruzada, en carta al Rey, informa de la favorable gestión que está desempeñando Gonzalo de la Maza y que cuenta con toda su ayuda ${ }^{51}$.

48 AGS, CCI, 573

49 AGS, CCI, 573 Panamá. 1600 7.10 G. de la M. Bulas del $N^{\circ}$ Reino robadas por los ingleses; eran de la $1^{2}$ predicación. Se suplieron con el duplicado de la anterior predicación.

50 AGS, CCI, 573. Año 1601, Lima. Esta oposición vendrá de encubridores como el notario Alonso Ramos de Caravantes, apelado "el bienaventurado", y que dirá del contador y del subdelegado que son "tiranos robadores" por los yerros que más adelante le descubrirán.

51 AGS, CCI, 573 . 
Desde Madrid, el 7 de marzo de 1601, le manifiesta el Consejo de Cruzada que "tiene tanta confianza de los buenos efectos de su ida de Vuestra Merced a esas provincias, se ha tenido y tiene muy gran cuidado hasta saber la llegada a Lima". Ante su enfermedad en compañía de su familiar, le animan a que goce de salud para emplearla en el ministerio que lleva, principalmente en que se pongan en cobro todos los alcances de los tesoreros pasados y se dé orden de los nuevos asientos con la mayor seguridad que fuere posible ${ }^{52}$.

Tampoco parece que el Contador recibiese la carta del Consejo pues el 17 de octubre de 1601 se dirige al Supremo Tribunal de Cruzada en términos dramáticos, casi jeremíacos, en los que advertimos las penalidades sin cuento que sufrió y la falta de comunicación con el Consejo. Por su gran interés transcribimos toda la carta:

"Ya VS habrá entendido que soy soldado muy antiguo des esta Santa Milicia y como el amarlo fue parte para sacarme no sólo de esa corte donde tenía más de lo que merecía, pero de entre mis señores, deudos y amigos, y traerme dos mil quinientas leguas de ellos como un caracol con la casa a cuesta a ponerla en tierra donde puedo decir que estoy tan sin esperantas de lo que perdí lejos de ellos y de tener amepentimiento de haber hecho tan largo viaje después que la buena nueva de tener a VS ${ }^{a}$ por dueño y amparo llegó a mi noticia pues con el no hay cosa de Job para mí ni que temer ni llorar sino la distancia de no poder en persona dedicarme al servicio de Vuestra Seftoría a quien humildemente suplico me admita en él sirviéndose de ponerme en el catálogo de los más verdaderos criados de su casa y mandarme como a tal que sería para mí la merced más estimada del este mundo [...] de los trabajos que se padecen ninguno siento más que verme hace 17 meses en las Indias sin ninguna carta ni aviso del Consejo ni de ninguno de los señores del Bien de este Estado. Estoy del regalo con que vivía y con ánimo para no hacer caso de trabajos a que me lleva. El deseo y esperanzas que tengo de con este favor de Nuestro Señor y de Vuestra Señoría dar buena cuenta de lo que se me encargo y encargare y nuestro Sr. ponga y guarde en la dignidad que merezco y yo deseo de las leyes 53 .

Sometido al Comisario Subdelegado, el empleo de Contador Mayor era el de mayor rango con un salario asignado de 3.000 pesos y derecho a situarse en los actos oficiales siempre junto al virrey. Pero no fue fácil el desempeño del cargo, pues habitualmente tenía que sortear numerosos obstáculos, como la falta de apoyo y hasta la oposición de los curas párrocos de indios.

F. López de Caravantes ${ }^{54}$, al enumerar jerárquicamente los miembros del Tribunal de Cruzada, coloca al Contador tras el Comisario y Asesor, infor" mándonos que percibía 3.000 pesos ensayados, con la obligación a su cargo de

52 AGS, CCl, 588.

${ }_{33}$ AGS, CCl, 573.

s4 Noticia...[420]. p.41.

Missionalia Hispanica

Hispania Sacra 48 (1996) 
contar con los Oficiales necesarios ${ }^{55}$ y poner libros, papel y tinta precisa para el despacho de su oficio. Pero al salario establecido se unían las propinas y las ayudas de costa que a veces incrementaban notablemente sus ingresos. A Gonzalo de la Maza, por ejemplo, se le hizo merced de tres mil pesos ensayados de ayuda de costa en la expedición primera de la Bula, y cuando salió de su Tribunal a tomar cuentas a los Tesoreros de Potosí le abonaron cuatro mil pesos ensayados por año durante el tiempo que duró su comisión.

\section{YERROS AL DESCUBIERTO}

El Subdelegado informa de la llegada del Contador el 29 de febrero de $1601^{56}$. Sin concederse tregua alguna por su falta de salud y cansancio, De la Maza comienza su tarea en la capital del virreinato. No se sabe del paradero de 4.000 bulas de vivos y 1.500 bulas de elifuntos. Informa Gonzalo de la Maza de una alcance de 4.839 pesos. Así, desde Lima, en 1601, el Contador nos informa de cómo consigue el alcance de 44.139 pesos, por las bulas sobrantes de Potos ${ }^{157}$. Por estas fechas, da cuenta al Rey y al Consejo de Cruzada de su cargo y el de J. Velázquez y cómo anda procurando las cuentas del asiento y pide se despachen bulas ${ }^{58}$. debe ayudar personalmente a Martín Maldonado, escribano de Cruzada por no tener salario ${ }^{59}$. En noviembre de $1601 \mathrm{De}$ la Maza relata los yerros averiguados en los tesoreros Miguel Sánchez de la Parra y J. Beltrán, 32.924 pesos.

El 19 de noviembre de 1601 escribe al Consejo de Cruzada quejándose del poco apoyo del virrey y la necesidad de orden real particular para las autoridades ${ }^{60}$. Este mismo día agradece la merced recibida del Consejo y Comisario, prometiendo trabajar con todas sus fuerzas en ganar la voluntad del virrey; envía una carta comunicando su gestión, pide más bulas, envía cuentas...Insiste de nuevo en la conveniencia de guardar las preeminencias y exenciones a los tesoreros y ministros de Cruzada, de acuerdo con lo tratado con el presidente y Audiencia de Lima. Transmite la dificultad de conseguir recaudar la limosna en el tiempo fijado y piden se le alarguen los plazos de los dos años concedidos para cada predicación. De la Maza considera oportuna esta merced

35 AGI, Contratación, 5262. Por los Libros de Pasajeros del AGl conocemos que con D. Gonzato de la Maza pasaron Juan Ochoa de Valda y Zárate, Diego de Alviz, Juan Sebastián Martínez, como oficiales.

36 AGS, CCI, 573.

57 AGS, CCl, 574.

58 AGS, CCI, 573, 15.10.1601, Lima.

59 AGS, CCI, 573. 19.11.1601.

60 AGS, CCI, 573. 
porque el dinero no estaría ocioso en la caja o prestado a otros y se lograría mayor puntualidad en la remisión por parte del tesorero pues él también la tendría en pagar con los registros presentes y sin permitirle ocasión de que se quede el dinero.

Informa de la mala calidad del papel de las bulas enviadas para Cartagena y Santa Marta "todas impresas en papel quebrado" advirtiendo que "si en alguna parte es necesario el honor y autoridad de las cosas por menudas que sean es en esta tierra aunque parezca que no importa nada". Nuevamente intenta ajustar la demanda de las bulas en función de la necesidad real. Así, de las 32.058 bulas enviadas considera que son suficientes 12.000 hasta que no se hagan más poblaciones. Con el fin de abaratar los portes y fletes es partidario que los fardos de 4.000 bulas que pesan 3,5 arrobas y pagan por cuatro se hagan de 5.000 bulas ahorrando 350 ducados en cada predicación. Anota por último un mínimo detalle pero que revela hasta qué puntillosidad desciende este competente funcionario. Parece ser que el tesorero de la Hacienda, Francisco de Cárdenas, se adueñaba indebidamente de las frazadas que envolvían los fardos que traían las bulas, para lo que nombró al letrado Licenciado Guerrero de Luna, con un salario 50 pesos, con el fin de resolver los pleitos movidos por ese hecho.

El punto referencial sobre la forma de tomar las cuentas fue Castilla. En primer lugar, por la legislación, en segundo lugar porque buena parte de los funcionarios se habían formado en Castilla en tribunales con operaciones similares y, por último, porque el órgano supremo de Cruzada, el Consejo, se ubicó en Madrid a lo largo de su dilatada extensión cronológica. Así lo pone de manifiesto el siguiente texto en que Julián Bravo, escribano del Tribunal de Cruzada, notifica que, al volver a tomar las cuentas de Cruzada de Juan Beltrán de Aparicio, tanto "las pasadas como de las por venir teniendo y glosando un libro aparte por el estilo y forma con que se toman y fenecen en la Contaduría Mayor de cuentas de Castilla"66. De igual modo se expresa la real cédula, de 25 de enero de 1600, dirigida al Arzobispo de Lima:

"Y por parecer así mismo que conviene a mi servicio y a la buena cuenta y razón que se debe tener de lo procedido de la dicha Cruzada, y para lo gastar y distribujr en los efectos para que ha sido concedido, y que las cuentas dello se tomen por el estilo y forma que en mi Contadurfa Mayor de las de Castilla se toman las de lo procedido en estos reinos, he nombrado al Contador Gonzalo de la Maza para que vaya a esas tierras [...] y les dé orden (a los tesoreros)para que de aquí adelanten las tomen por el estilo de la dicha mi Contaduría Mayor de cuentas de Castilla62".

\footnotetext{
${ }^{61} \mathrm{AGS}, \mathrm{CCl}, 561$.

${ }^{62}$ AGS, CCI, 56].
} 
Un año después se le vuelve a recordar ${ }^{63}$ que el modo y manera de tomar las cuentas y lugar por el Contador Gonzalo de la Maza sea como en la Contaduría Mayor de Castilla, con un oidor y los Oficiales Reales.

Sus frecuentes cartas recogen temas relacionados con su gestión, tales com mo el descuido de Portobelo y Panamá en enviar bulas y despachos a Lima ${ }^{64}$. No menos abundantes son las cartas encomiásticas del Consejo, como la que le dirigen desde Madrid 7 de marzo de 1601, preocupados por su salud: "Como el Consejo tiene tanta confianza de los buenos efectos de su ida [...] cuide su salud para emplearla en el servicio de Su Majestad ${ }^{65 " .}$

En otras ocasiones, manifiesta al Rey, a través del virrey de Perú, la situación real y concreta de sus súbditos, tal como la conciencia de agravio sentida por los mestizos al igualarles en en las tasas de las bulas con los indios"66.

A finales de 1601, 22 de diciembre, da cuenta al Consejo de Cruzada, en la persona de los consejeros Luis Valle de la Cerda y Juan de Chavarri, del estado de su gestión. En su detallada carta pasa revista concienzuda a todos los asuntos relacionados con la Bula de Cruzada. El monto de los derechos de los despachos de estas provincias de las 4 predicaciones últimas de la segunda concesión. Los de las 2.000 instrucciones de la $5^{\mathrm{a}}$ predicación de Juan Beltrán Aparicio, lo escribió en cartas de 29 y 30 de abril son 367.418 maravedís. Informa también de las 2.000 instrucciones que fueron para la $6^{\mathrm{a}}$ predicación, de la muerte de Juan Beltrán Aparicio y el nombramiento de tesoreros por menor por partidos y así se les entregaran los despachos desmembrados y, entre todos, recibieron 927 solamente de los 2.000 , quedando los 1.073 restantes en la Casa de Contratación de esta ciudad con las bulas sobradas... Lamentación por pedir 2.000 despachos cuando no hay siquiera mil pueblos. La única explicación es que Beltrán nunca pagó derechos ni se le pidieron. Termina comunicándoles lo que procura introducir y "lo poco que se aprovecha...y que yo acá estoy pospuesto a_todo lo que se me ordenare y sucediere ${ }^{67 "}$.

\section{CUENTAS CLARAS Y REVISIÓN PRECISA}

El 6 de abril de 1602 se le solicita que vaya a Quito para ver el estado de las cuentas de la primera concesión e inspeccionar la gestión del tesorero Ro-

\footnotetext{
${ }^{63}$ AGS, CCI, 573. 20.XII.1601.

64 AGS, CCI, 573. 22-12-1601.

${ }^{65}$ AGS, CCI, 588 .

66 AGS, CCI, 588

${ }^{67}$ AGS, CCI, 573.
} 
drigo de Carbajal ${ }^{68}$. Se le autoriza para administrar por menor la tesorería de Cruzada desde la $3^{a}$ predicación. Denuncia que los comisarios y ministros admitiesen cesiones y poderes de particulares para cobrar sus deudas a título de Cruzada sin serlo. Toma asientos con Cano de Nebrija (Lima), J.A.Baeza (Cuzco), Gutiérrez Velázquez en Charcas, A. Castillo (Quito), L.Pérez de la Laguna.

En carta de 2 de mayo de 1602 el Contador relata los "Caminos largos y trabajosos" recorridos en su ardua tarea de revisar las cuentas junto al comisario J. Velázquez. Da cuenta también de la postura hecha por Gerónimo del Valle acerca de la tesorería de Cruzada con la posibilidad de comerciar con China, sin pagar la necesaria licencia de 100.000 ducados. Afirma que sería muy buen ofrecimiento, pero que con tal condición no era conveniente ${ }^{69}$.

En el extracto de la nueva carta se pide el asiento del Tribunal con asesor y fiscal de Audiencia. El excesivo trabajo del notario, que MaIdonado se vuelve rechazando el oficio y cómo conviene dar al actual 300 pesos de salario por lo menos. Al alguacil se le deben dar 100 pesos de lo procedido de Cruzada y otros 100 pesos en los bienes de los tesoreros M. Sánchez de la Parra y J.B. Aparicio, convendría darle, en lugar de derechos de ejecuciones y diligencias, un salario de 200 pesos y se encontraría persona para tres años. Que el cargo de solicitador fiscal nombrado con acuerdo del virrey con 250 pesos de salario, lo desempeñe el fiscal de la Audiencia. El depositario sobre los bienes de acreedores de Aparicio y Parra, por el conflicto con los Oficiales Reales, no se dé salario pues durará poco. Pide orden en el recibimiento de la bula; engaño en el asiento de Charcas y en el de J.B. Aparicio; es partidario de conceder la bula a través de las Cajas de Comunidad; pide breviarios, cuchillos y cédulas para premiar a los ministros de la doctrina; pide también se concedan las preeminencias para los tesoreros y ministros de Cruzada; se evite que el Comisario Subdelegado nombre otros subdelegados particulares en las cabezas de partido; señala los inconvenientes observados en la administración de las cuentas declarándose partidario de que tome las cuentas un oficial real junto con el contador de Cruzada con sus libros respectivos y en presencia del fiscal; informa de la quiebra de los dos tesoreros Parra y Aparicio; de este último se forma un alcance de 73.195 pesos que prevé cobrar en su totalidad; debido a su labor los tesoreros particulares van siendo muy puntuales; denuncia el descuido en Tierra Firme en el envío de las bulas; comunica las razones de su marcha a Quito y el salario concedido con asistencia del virrey; envían arancel de los derechos de comisario y notarios de Cruzada ${ }^{70}$.

68 AGS, CCI, 573.

AGS, CCI, 573.

70 AGS, CCI, 573 .

Missionalia Hispanica

Hispania Sacra 48 (1996) 
En Valladolid, en el mes de septiembre de 1602, se plantea una consulta al Consejo del Rey, en la que se constatan los beneficios producidos por la administración del Dr. Velázquez y el Contador. Se han rescatado más de 160.000 ducados de los que ya se han enviado 60.000 pesos en la flota de Tierra Firme. Como ayudante se propone como asesor al oidor don Juan de Villela y por fiscal al licenciado Joan Páez de Laguna con 250 pesos ensayados de salario cada uno al año. Se advierte de la necesidad de anotar todo en un libro de archivo y de que pongan la limosna en arca aparte. Constatan la decisiva influencia de los doctrineros en la predicación y cómo deben estimularlos obsequiándoles con breviarios, diurnales y cuchillos. Como premio a la labor del Contador proponen darle voto en el Ayuntamiento de Lima como los Oficiales Reales. Por su parte, solicitan 2.000 pesos ensayados de ayuda de costa para el Comisario ${ }^{71}$.

Un mes más tarde, 15 de octubre de 1602 , conjuntamente con el subdelegado, se dirige al Rey dando cuenta del estado de la Cruzada. Informa de la revisión de cuentas efectuada obteniendo del primer tesorero Miguel Sánchez de la Parra 53.937 pesos, y del segundo J. Beltrán 78.538 pesos. Tanto uno como otro se apoyaron en la mala gestión de Alonso Ramos Caravantes, notario de Cruzada, al que acusan de connivencia con los Oficiales Reales, incluso con el virrey de encubrir a los tesoreros.

Esta operación de "limpieza" le acarreará al subdelegado J.Velázquez de ser "el hombre más bienquisto y querido de la ciudad" a ser criticado, sólo por causa de "su entereza y rectitud"; por supuesto de la insidiosa campaña de desprestigio "no queda libre el contador como especulador de estas cosas y de ver que con su venida se hayan desenvuelto y sacado a luz". Sin embargo -afirma- el fuerte don Gonzalo "todo esto se lleva en paciencia y buen ánimo ${ }^{72 "}$.

En apoyo de su gestión solicitan del Rey que escriba a todas las autoridades motivando el apoyo y favor de la Bula de Cruzada. Justifican su rigor por la falta de apoyo de las mismas. Así, el propio virrey no atiende la petición de dar un asesor para pleitos. Nuevas gestiones consiguen que el 19 de noviembre se nombra a D. L. de Larrinaga

Este mismo año da cuenta de enviar en la Armada de 160255.591 pesos, más 67.092 Reales por lo ingresado en las Cajas de Lima y Potosi ${ }^{3}$.

En octubre de este año de 1602 le nace su primera hija en Perú, Micaela, que fue bautizada el día 20 en la parroquia de la Catedral, y que más adelante contraerá matrimonio con el segundo contador de Cruzada, Andrés de Zavala.

71 AGS, CCI, 573.
72 AGS, CCI, 573.
73 AGS, CCI, 576.

Missionalia Hispanica Hispania Sacra 48 (1996) 
El 1 de marzo de 1603, inicia la revisión de cuentas en Charcas y Tucumán en las tesorerías de Juan de Espinosa-Juan Sanz de Galarza. La espinosa gestión no termina hasta 1610, prolongándola en Cuzco. En 1605 se reconocen sus meritorios servicios:

\footnotetext{
"la gran satisfacción con que se queda del cuidado y diligencia que por Vuestra Merced se ha puesto y pone así en la administrạción de esa gracia como en el aumento de ella y cobranza de los alcances que todo muy particularmente se ha representado a Su Majestad y lo mucho que el contador Gonzalo de la Maza ha trabajado en los viajes que ha hecho y el beneficio que hay y se espera en la Real Hacienda de todo esto se tendrá cuenta para hacerle mayor merced como la merece ${ }^{74^{n}}$.
}

El 14 de noviembre de 1603 recibe una real cédula desde El Escorial para que el Subdelegado General se junte 3 días a la Semana con el asesor y fiscal nombrados. Asistimos a los primeros pasos de la fundación de los tribunales de Cruzada en Perúp ${ }^{75}$.

En el mes de diciembre de.este año de 1603 le nace su segunda hija, Andrea, que fue bautizada el 30 de diciembre en la parroquia de la catedral de Lima.

El 15 de mayo de $1605, G$. de la Maza, junto al comisario Velázquez y el asesor Villela, recuperan 90.287 ducados del tesorero Juan Sanz de Galarza. Casi un año después, el 20 de mayo de 1606, envían en la armada 72.592 pe$\operatorname{sos}^{76}$. A los cinco días, se comunica la suspensión de su visita a Quito por no haber recibido aviso de llegada de bulas de la cuarta predicación.

Una real cédula de 18 de agosto de 1607 comunica el aumento de 1000 pesos en el salario de G. de la Maza, sumándolos a los 2.000 que percibía ${ }^{77}$.

El 26 de mayo de 1608 se nombra fiscal del tribunal de Cruzada de Lima a Juan Pérez de Laguna para que ayude al Dr. Velázquez y G. de la Maza ${ }^{78}$.

\section{"UN AMIGO MUY FIEL Y VERDADERO"}

El notario de Cruzada, Juan de Tamayo, comunica que en la flota del año pasado se escribió largamente en respuesta de todas las cartas recibidas en el Consejo y cómo

\footnotetext{
74 AGS, CCI, 563.

${ }^{75}$ AGS, CCI, 588, 1603 Títulos y cartas de Su Majestad. Al Conde de Monterrey: Nombramiemo de Jaan de Villeja y Juan Páez de Laguna para ayudar a G. de la Maza.

76 AGS, CCI, 573.

77 AGS, CCI, 576.

78 AGI, Indiferente, 2865.1.
}

Missionalia Hispanica

Hispania Sacra 48 (1996) 


\begin{abstract}
"con ésta va un duplicado de la general y por ponerse en ella todo tan en particular habrá poco que advertit pues la satisfacción con que se queda del cuidado y diligencia con que ustedes proceden en sus oficios asegura el buen gobierno y aumento de la Cruzada como se va viendo por experiencia y para que todo se gobjerne con más autoridad y deliberación, se envían con ésta las cédulas que entonces no pudieron ir por algunos estorbos que hubo. Informe favorable por el buen cariz de la gestion del contador". Visita acertada al Cuzco por la falta que había de predicación en muchos lugares; lo mismo sucedió con Charcas y Quito. Comprobación de los alcances de Miguel Sánchez de la Parra y ver si se puede cobrar de los juros de D.Jorge de Urrea y cómo las diligencias han sido muy buenas. Ídem de los alcances de Juan Beltrán. También de la sexta predicación de Lima de Antonio Ponce; igualmente de Santiago de Chile con Gaspar Jorge de Segura y el duplicado de Panamá. Y todas los que se refferen en la carta del Contador vienen con la "forma y curiosidad que siempre suele".
\end{abstract}

Se le pide haga un resumen de todas como balance final y se vea si los tesoreros generales del primer asiento quedan a deber algo en todas las provincias que tuvieron a su cargo y si fuera necesario da dos pliegos en Nueva España para que se dé razón allá de todo ${ }^{79}$. De esta manera, en marzo de 1609 , podían dar cuenta de los alcances obtenidos desde 1588 en los tesoreros M.Sánchez de la P. y Juan Beltrán, consiguiendo un aumento considerable ya que si en el último cuarto de siglo y primeros veinticinco años de la implantación de la bula en Indias, 1574-1600, Ia limosna de cada predicación solía ser de 33.374 ducados, en este momento, año 1609 , eran 77.533 ducados, mucho más del doble 80 . La razón fundamental la expone el mismo contador De la Maza en la carta de marzo de 1610 " la inclinación y entrañable amor que tengo a las causas del ministerio de la Cruzada por el curso incansable de 30 años y más tiempo que ha que sirvo a Vuestra Majestad en la administración y cuentas de ella ${ }^{81 "}$. El Consejo de Cruzada, desde Madrid, ante mejora tan considerable, no regatea palabras para agradecer su gestión ${ }^{82}$. Gestión que por otra parte no queda confinada al campo específico de la contaduría de Cruzada sino que tiende sus ramificaciones hasta los más intrincados campos de la administración indiana. Así, en 1610, emite un informe sobre las minas de azogue de Huancavélica en que pondera utilidades del socavón ${ }^{83}$. Un año después, 1611, debe aplazar su viaje de inspección o revisión de cuentas a Quito por resolver problemas con el virrey; tuvieron que nombrar a Juan de Tamayo en su ausencia ${ }^{84}$. El 27 de julio de este mismo año, siempre pronto a prever el futuro de la administración de la Bula de Cruzada avisa del inconveniente que

\footnotetext{
79 AGS, CCI, 573.

si) AGS, CCI, 586.

81 AGS, CCI, 573.

82 AGS, CCI, 573. Madrid, 18.10.1610.

${ }^{83}$ Biblioteca Nacional de Madrid, Manuscrito 304I, f.172.

$84 \mathrm{AGS}, \mathrm{CCI}, 573$.
} 
le suceda en su oficio el oficial más antiguo ${ }^{85}$. Aunque meses después, el 23 de marzo de 1612 por una real cédula se le concedía a G. de la Maza la merced de 2.000 ducados como ayuda de costa ${ }^{86}$, sin embargo se advierte nueve meses después que se evite el salario del factor que le ayudaba en su tarea administrativa ${ }^{87}$. Comprendemos, ante su agotadora tarea, su lógica petición de "alguna quietud para lo poco que le queda de vida y no dejar en aquella tierra con desamparo y pobreza mujer de hijas"88.

El biógrafo de santa Rosa, J.M. Bermúdez, nos ofrece algunos datos sobre el Contador:

"El contador don Gonzalo de la Maza (DGM) y su digna consorte Da María de Uzátegui (DMU), hicieron el más brillante papel, en los últimos cinco años de la vida de nuestra Rosa. Así es indispensable coronar esta historia con la debida mención de su virtud y mérito. Era DGM natural de Ogarrio, valle de Ruesga en las montañas de Burgos y señor de la casa y solar de su apellido. Casado con DMU nacida en Madrid. Pasó en su compañía al Perú en el año de !601, encargado de algunos negocios gravísimos de Real Hacienda que se le confraron por su mucha experiencia e integridad que mostró en 22 que sirvió de contador de Fábrica del Monasterio del Escorial y de contador ordenador de resultas de la contaduría mayor de Castilla. Vino comisionado para visitar el tribunal de cuentas y establecer el de la cruzada: siendo su primer contador mayor, plaza que por entonces por juro de heredad en sus descendientes. Este varón a todas luces grande, de singular ejemplo, aprobación y verdad, aunque benefactor muy estimado de Rosa, no fue su padrino, como vulgarmente se ha pensado ni pudo serlo. Pues cuando dicho señor llegó a Lima ya la santa contaba 15 años y por consiguiente estaba bautizada, teniéndola en la pila Hernando de Valdés y María Orosco como aparece de su partida de bautismo [...] Habiendo entendido la madre de Rosa cuanto agradaba a su hija el trato de aquella piadosa familia que la tenía consigo y la apreciaba tanto pasó a darle tas gracias a la señora Uzátegui y se la entregó para que dispusise de ella como de hija".

Promete obediencia a don Gonzalo, su esposa e hijas y hasta la menor de sus esclavas. Al ver tal perfección le instó a Rosa a que ingresase religiosa en el monasterio de Descalzas de san José ofreciéndose a pagarle la dote.

"Por recomendación de DMU confirió también con el maestro fray Juan de Lorenzana, célebre dominicano a quien últimamente rindió la obediencia con grandes progresos de su espíritu... Habitaba de día y parte de la noche, encerrada en el oratorio o aposento más retirados. [...] Se hacía admirar por la abstracción de sus sentidos, la compostura de su cuerpo y modestia de sus ojos, que pocas veces se los vio levantar DGM, con ser tan familiar que la llamaba Madre y ella a él Padre... En los días de Jubileo de cua-

\footnotetext{
8.5 Ibídem.

R6 AGS, CCI, 576.

B7 AGS, CCI, 573.

as AGS, CCI, 576. Lima, 3 de marzo de 1613.
}

Missionalia Hispanica

Hispania Sacra 48 (1996) 
renta horas se quedaba hasła la noche, encargándose de acompañarla la señora Uzáteguig9".

En 1614 se nos notifica una de las pocas quejas vertidas con hacia el notario de Cruzada, Juan de Tamayo, nos informa de ciertas desavenencias entre Gonzalo de la Maza y J. Velázquez. La culpa parece ser del subdelegado Velázquez que se une a su familiar Dr. Carrasco ${ }^{90}$, y no de nuestro contador. De esta fecha precisamente es también la Relación del Marqués de Montesclaros, virrey del Perú a su sucesor, en la que se nos muestra el estado de la Bula de Cruzada en Perú y la alta estima de que gozaba nuestro Contador al que se califica de "amigo muy fiel y verdadero"1".

Tal verdadera amistad se manifiesta en la permanente correspondencia mantenida con el Rey a través del Consejo de Cruzada. Lo comprobamos en 1615 , en un memorial dado el 23 de enero a SM de Gonzalo de la Maza por el que informa de la cobranza de 263 ducados a $\mathrm{A}^{\circ}$ Ramos Cervantes, notario de Cruzada durante 20 años y por quien "todo anda muy descompuesto"92. Cuatro meses después avisará de cómo el oficio de tesorero es poco apetecido y se ponga remedio. En el mismo mes de mayo envía tres cartas al Comisario General abogando para que los subdelegados de cruzados sean juristas como Feliciano de la Vega y no teólogos como lo era Juan Velázquez; ello no obsta para pedir que hiciese merced a éste por la ingente tarea desarollada ${ }^{93}$. En este mismo mes el Tribunal comunica al Rey que el Contador se detenga en Lima, antes de ir a Quito, para defender los pleitos de Hemando de Soto y Juan de Leto ${ }^{94}$.

Por estas mismas fechas se ordena que el Contador tome las cuentas con uno de los contadores del Tribunal de Cuentas nombrado por el virrey, Domingo Garro primero y, posterionmente, Alonso Martínez de Pastrana. Según una real cédula de 25 de enero de 1616 el Consejo ordenó que se tomasen conjuntamente las cuentas de Cruzada por el contador de ese Tribunal y uno del de Cuentas para no tener que recurrir a España para obtener el finiquito. El virrey Esquilache designó a De la Maza en primer lugar, orden que fue objetada por la contaduría ${ }^{95}$. Entre las minutas de cartas de don Gonzalo, en 1617, hay una de 8 de abril en la que advierte que no hay demasiado fundamento en

g9 J.M. BERMúdeZ: Vida de la gloriosa virgen dominicana santa Rosa de sana María Lima, 1827. Reimpresión de UNIFE, Lima, 1987.

"9) AGS, CCI, 576.

9112 de diciembre de 1615. Colección... [37] 6. pp.187-273.

92 AGS, CCI, 576.

9.3 Ibidem.

94 Ibídem.

95 AGI, Lima, 105. 
la pretensión de los contadores de cuentas al afirmar que son superiores a los de Cruzada basándose en que

"en estos reinos se toman las cuentas de Cruzada en contaduría mayor" [...] "sin advertir que cuando ellos despachan por don Felipe [de Tasis, comisario general] es cuando el virrey interviene y asiste y que la voluntad de Su Mag. conforme a su real cédula no es que estas cuentas se tomen en el tribunal de cuentas sino que uno de los contadores de cuentas le ayude a tomarlas y el tribunal de Cruzada es de más autoridad del suyo pues asiste con el subdelegado general un oidor de la Real Audiencia y un fiscal a quien él prefiere y que el fiscal en cualquier Junta y en su mismo tribunal les prefiere a ellos ${ }^{\prime \prime}$ ".

En 1616, el notario de Cruzada, Juan de Tamayo, pide que Gonzalo de la Maza vaya a Quito a recoger cuentas del tesorero Miguel Sánchez de la Parra por un valor de 4000 pesos. Este mismo años, desde Ancash Recauay, el bachiller Diego de la Vega ante el escribano de SM dijo que daba su poder al Contador G. de la Maza, residente en la ciudad de Los Reyes, para que en su nombre se pudiese oponer a cualquier doctrina y beneficio de este Arzobispa$\mathrm{do}^{97}$.

El 27 de abril de 1619, G. de la Maza da cuenta de una relación de la plata enviada de sus 5 distritos. En Cuzco, Guamanga y Arequipa se deben 3.500 pesos $^{98}$.

\section{A QUIEN ROSA DE LIMA LLAMÓ PADRE}

Su recto proceder profesional nacía de una poderosa vida espiritual como se constata en la íntima relación vivida con la santa limeña ${ }^{99}$. M.T. de Bussièrre recoge el asombro producido, tanto en sus contemporáneos como en los historiadores, sin aventurar las motivaciones últimas que le llevarían a Rosa a tomar como domicilio habitual la casa del contador ${ }^{100}$. Doña María Usátegui nos saca de dudas, desde su condición de confidente de Rosa. Con su familia, conoció a la santa limeña, en 1612, cuando ella había cumplido los 26 años ${ }^{101}$. Vivían ambos consortes con sus hijas Micaela y Andrea en la calle del Capón,

96. AG, CCI, 576.

97 Archivo Arzobispal de Lima, Catálogo General de Visitas, Leg. l.

98 AGS, CCI, 576.

9) AGI, Lima, 1613 .

160 M.Th. de Bussière: Le Pérou et sainte Rose de Lima París, Víctor Palmé, 1863. "Les historiographes se bornent à rapporter le fait, mais n' en font pas connaître les motifs". p.407.

lo1 Cayetano Bruno: Rosa de Santa María. Lima, 1992. Editorial Salesinna. La mayoría de los datos de este apartado son deudores de esta obra que a su vez tienen como fundamento los manuscritos $n^{\circ} 1570$ y 1573 de la Sagrada Congregación de Ritos del Archivo Secreto Vaticano.

Missionalia Hispanica

Hispania Sacra 48 (1996) 
a espaldas del actual monasterio de Santa Rosa, y deseando el uno y la otra conocer a la sierva de Dios "por la noticia que tenía de su mucha virtud", hallaron al fin la coyuntura favorable que así refirió la de Uzátegui, el 15 de julio de 1630, 13 años después del fallecimiento de la Santa. Doña María Usátegui "se la llevó a su casa ${ }^{102}$, y pidió a su madre que se la enviase otras veces; la cual lo hizo", a solaz del contador de la Maza, que celebró alborozado el encuentro, pues comenzó Rosa a ser muy adentrada en el nuevo hogar. $Y$ hasta la madre de la santa, Isabel Oliva, se fue haciendo a la idea de que mejor lo pasaría su hija, agotada por las enfermedades y las atenciones de la casa, en tan recomendable hogar; aunque repugnándolo ella, pues le pareció que "no era razón, viendo (a) sus padres enfermos, dejarlos".

La única dificultad que ponía Rosa era mantener en la nueva morada su vida penitente y de casi total encierro. "Le dijo muchas veces la Santa -expuso Fray Luis de Bilbao- pidiese a su madre, que también era su hija de confesión, que no la enviase a casa de una señora principal que la quería mucho, porque la importunaba que comiese".

Por fin llegaron a un acuerdo: "La habitación de la dicha Rosa en la casa de este testigo fue con gusto de los dichos sus padres, y con el de los padres espirituales con quien se comunicaba, y aun algunas veces ordenado por ellos, como se lo dijeron a este testigo el padre maestro Lorenzana, de la Orden de Santo Domingo, y el padre Diego Martínez, de la Compañía de Jesús, sus confesores".

Allí vivió Rosa año y medio, supuesto que en los últimos tres años y medio de su vida lo pasó sobre todo en la celdita y huerto de la casa paterna. "La tenía en su recámara en compañía de dos hijas de esta testigo. En la cual (recámara) y en el oratorio que tiene en la dicha su casa, era su ordinaria habitación, y también asistía en la cuadra, donde labraban y cosían esta testigo y sus hijas, y algunas veces iba a casa de su madre por cinco o seis días, y luego se volvía". El biógrafo de la santa, J.M. Bermúdez, señala que "dedicaba algunos días u horas a la enseñanza de las niñas del contador ${ }^{103 "}$. El alto grado de intimidad alcanzado entre Rosa y las jóvenes hijas de don Gonzalo convirtió a la terciaria dominica en su mejor amiga, educadora y directora espiritual. Así nos lo revela J.M. Bermúdez: "Doña Micaela de la Masa, hija del contador Don Gonzalo de la Maza, trataba consigo misma ciertos asuntos que a nadie había comunicado, ni pensaba hacerlo. Llegósele Rosa familiarmente y le refirió cuanto meditaba. Diole reglas saludables para su gobierno: Dejándola

\footnotetext{
102 LUIS Getino: La Patrona de América anve los nuevos doctintentos. Madrid, Imprenta de E. Giménez, 1927, reedición de 1937. p.14.

103 Relación de Rosa con la familia de don Gonzalo de la Maza C, 2 "Vida de Santa Rosa de Lima". Lima, Imprenta de los Huérfanos, 1827. p. 145.
} 
llena de admiración y espanto, viendo penetrados los secretos de su corazón ${ }^{104 "}$. Por esta razón, no nos extraña que cuando Rosa se despedía de este mundo, ante la muerte que sabía de antemano, "no se olvidó de las dos niñas, hijas del Contador, a las que amaba por su inocencia y buen natural, y les encargó el temor de Dios, la práctica de la virtud y el honor de sus progenitores ${ }^{105 "}$.

La familia De la Maza se convirtió en su auténtica familia. El confesor Lorenzana le daba licencia para recogerse en casa de Don Gonzalo de la Maza "donde la curaban y servían con el mismo amor que si fuera su hija". También le buscaron un confesor ejemplar: "Dijo que, aunque años antes tuvo noticia que una doncella de grandes virtudes y grande penitencia se confesaba en este convento, de quien decían algunos religiosos que había de ser otra Santa Catalina de Siena, pero no trató ni comunicó a la dicha santa virgen hasta el año de 1614, en que el Don Gonzalo de la Maza pidió a este testigo se encargase del alma de la bendita virgen Rosa, y de confesarla, y ser padre y guía de su vida...;(y), rogado e importunado, lo aceptó, y desde entonces hasta que murió la dicha Santa fue su confesor y padre, que fueron tres años y tres meses". A la Santa le tiraba la soledad amándola tanto que Doña María Usátegui, su confidente, "le oyó decir muchas veces que quería que se usara todavía la vida de los desiertos" para entrarse en ella. Consiguió su propósito con la celdita del huerto en la casa paterna donde vivió los últimos tres años y siete meses. Sólo algunos días antes de su última enfermedad volvió a la casa del Contador donde falleció.

La casa se convirtió en centro de espirituales tertulias ${ }^{106}$ en las que participaban selectos cristianos limeños, fundamentalmente seglares como Luisa de Melgarejo, esposa del rector de la Universidad de San Marcos en 1615, doctor Juan de Soto; el médico Juan del Castillo, hombre de ciencia y de gran caudal de cultura mística quien examinó a fondo y nos ha legado su espiritualidad a través de sus escritos ${ }^{107}$; además figuraban varias "beatas" como Ana María Pérez, cocinera mulata en el hogar del Contador, Inés de Velasco, sevillana

n4 Ibídem, p.104.

10s Ibídem, p. 127.

106 Archivo Histórico Nacional, Inquisición, libro 1030, f.211 v.

${ }^{107}$ Era natural de Toledo y según M.MENDiburu Diccionario histórico biográfico del Perí Lima, Imprenta E. Palacios, 1933: "profundo místico y de vida ejemplar. Tuvo largas điscusiones con Santa Rosa y examinó con madurez sus principios religiosos, doctrinas y prácticas de moral y santidad". IV, p.97. Aunque laico, fue director espiritual de Rosi, ingresando al final de su vida en la orden dominicana.

Missionalia Hispanica Hispania Sacra 48 (1996) 
casada con el comerciante Fernando Cuadrado; Isabel de Ormaza, india limeña ${ }^{108}$.

Tanta familiaridad nos lo revela el hecho de que María de Uzátegui acometiese el protagonismo de ingresarle en un convento por deseo expreso de su madre $\mathrm{D}^{\mathrm{a}}$ Oliva. Doña María de Uzátegui será la que "quitó de la cabeza (la corona de espinas) cuando cayó mala de la enfermedad con que falleció".

Van a ser testigos de su caridad heroica. "Porque tenía imposible que se pudiese contener en el dejar de servir a los pobres, a los cuales procuraba acudir con todo lo que podía y permitía su gran pobreza, y donde no, vido que se angustiaba y afligía" - según el P.Loayza. De tal manera que "aunque estuviese ocupada en la oración y recogimiento, habiendo algún moreno enfermo en casa de esta testigo, acudía a todas horas a curarle y regalarle".

Lo mismo puede decirse de su vida contemplativa. Así nos lo manifiesta $D^{a}$ María:" Sabe porque lo vido, que algunos viernes no podía responder ni hablar cuando ella se encerraba desde el jueves en la noche hasta el sábado por la mañana; y preguntándola esta testigo...Ia causa, Ie dijo que no la llamasen aunque viniese su madre, porque de ninguna manera podía responder ni levantarse de donde estaba, porque estaba arrebatada toda". Su oración la expresaba en la canción en la que quedaba embebida toda la familia:

"Y otras muchas cosas y palabras de grande amor y regalo, con linda voz y consonancia, que nos hacía dejar lo que hacíamos por estarla oyendo y escuchando... Y les sucedio a esta testigo y al Contador su marido, que dejaban de cenar por oír cantar a la dicha bendita Rosa".

Su conversación era marcadamente espiritual: "Tenía (Rosa) muy grande amor a un Niño Jesús que ésta testigo tiene en su oratorio, y algunas veces entrando el Don Gonzalo de la Maza su marido, al oratorio a decir requiebros al Niño Jesús le decía esta testigo a la dicha bendita Rosa:

- Mira, hija, qué enamorado está el Contador de su lindo Niño. Y decía ella:

- Muy bien puede, porque el Niño se alegra en viéndolo entrar, y parece que se quiere saltar de la peana y venírsele a los brazos.

También serán testigos de su despedida terrena. Les asombraba que mientras "la naturaleza iba desfalleciendo, parecía se aumentaba su paz y alegría". Y estando así el martes por la noche del 22 de agosto, "con un crucifijo en la mano, con amorosos requiebros le pedía dolores":

128 IwASAKI CAUTL, F. Mujeres al borde de la perfección: Rosa de Santa María y las alumbradas de Lima. Hispanic American Historical Review, 73.4, Nov. 1993, pp.581-613. AGI, Lima, 1613.

"Santos y Alumbrados: Santa Rosa y el Imaginario timeño del siglo XVII", Los Dominicos y el Nuevo Mundo. Actas del hl Congreso Internacional. Madrid, 1990. 
- Mi Dios, mi Señor, mi Jesús, mi Esposo, y mis amores, dadme dolores.

Se va despidiendo tiernamente de todos sus familiares. Comenzó pidiendo la bendición al Contador; y luego, llamando a sus dos hijas "les hizo una plática, exhortándolas a que sirviesen y amasen mucho a Nuestro Señor y sirviesen mucho a sus padres y les diesen buena vejez".

Por estos testimonios últimos sobre el momento de su muerte podemos calibrar el alto nivel espiritual de estos esposos:

- (DMU) Llamando ef dulce nombre de Jesús expiro, quedando con los ojos abiertos y claros sin quebrárseles, y su rostro tan lindo y hermoso como cuando estaba viva y con muy buenos colores.

- (DGM) Y con esta resignación, paz y entendimiento, y con su habla y sentido estuvo hasta que expiro, un poco antes de las doce y media de aquella noche, diciendo: "Jesús, Jesús sea conmigo".

Juan Costilla de Benavides, oficial mayor de la Contaduría de Cruzada, que vivía con el de la Maza, y se halló presente al fallecimiento, expuso que este fue exactamente dando las doce y cuarto, es a saber a las cero y cuarto del día de S.Bartolomé.

\section{LITIGIOS, ACHAQUES Y SUCESIÓN EN EL CARGO}

El Virrey consulta con D.Gonzalo de la Maza la posibilidad de suprimir el Tribunal de Cuentas en 1618; se niega argumentando que los problemas se deben a la falta de personal. Según López de Caravantes "ministro de mucha noticia y experiencia en la administración de la Real Hacienda"109. Una buena prueba de su "mucha experiencia" nos la da el registro de los Oficiales Reales de la Casa de Contratación de Sevilla acerca del dinero que vino de Indias en la flota de 1620 por G. de la Maza, un total de 49.493 pesos ensayados 25.991 pesos corrientes y 5.109 pesos de penas pecuniarias.

Desde 1620 , las fuerzas físicas comienzan a faltarle. Ésa es la causa principal de no cumplir puntualmente con los finiquitos de las cuentas:

"Dicen que por ta falta de salud que el contador DGM ha tenido de 8 meses a esta parte y hallarse fatigado de achaques penosos y continuos aunque al presente quedaba con alguna mejoría, no se han fenecido las cuentas que estaban en estado que se han

${ }^{109}$ R. Escobedo ManSiLLA: Control fiscal en el virreinato peritano. El Tribunal de Cuentas. Alhambra, Madrid, 1986. p.972.

Missionalia Hispanica

Hispania Sacra 48 (1996) 
ajustado por tanteo y que en saliendo del despacho de la Armada trataron de su fenecimiento $110^{11}$

Sabemos por una carta del notario de Cruzada de Lima, Juan de Tamayo, al Comisario General, Martín de Córdoba, que "tiene muy corta salud porque aunque está mejor su enfermedad es de piedra que hay pocas semanas que no eche 2 ó 3 y que así no hay que fiar mucho en su memoria'll".

El Dr. Velázquez, subdelegado de Cruzada en Perú, y Juan Jiménez de Montalvo, asesor, el 3 de mayo de 1620, informan de la limpieza con que ha servido Don Gonzalo de la Maza, 20 años en Castilla, 23 en Indias. Pese a haber empeñado 43 años de su vida en la espinosa tarea de la Hacienda Real, no tiene para remediar a sus hijos, solicitando merced del oficio de contador por otra vida para casar a una de sus hijas con

"persona calificada y que sea a propósito para aquel ministerio y que haciéndole esta merced aunque enfermo no se abstendrá del trabajo y industriará a la tal persona de manera que cuando falte la suya la causa de la Cruzada quede con ministro cual convenga para su mayor bien y que esta merced se le hizo a los contadores Luis Valle de la Cerda y Juan de Chavarri 112".

Este mismo año, en dos cartas distintas, una de abril y otra de mayo, Don Gonzalo de la Maza señala las diferencias del Tribunal de la Plata con el arzobispo sobre las licencias de oratorios y la necesidad de licencia por parte del ordinario; informa también a SM sobre lo mal que llevan la subordinación los tribunales de La Plata que se sienten agraviados ${ }^{113}$. Vemos cómo sigue gestionando al detalle la contaduría. Así, el 6 de mayo de 1622, pide que se envíen los pareceres en razón del arca de 3 llaves -creada por real cédula de 1603-de poner el dinero en arca aparte y se envien menos bulas de vivos de 2 tomines para Chile ${ }^{114}$.

Varias de las cartas se dirigen a hacer valer los derechos de su yerno Andrés Zabala, como, por ejemplo, la de 24 de mayo de $1620^{115}$. Un año después, insiste en la petición pidiéndole que de momento le supla en sus ausencias como merced a sus servicios. El 25 de abril de 1622 informa de su escrito al Tribunal dando 116 el estado de las cuentas, al tiempo que representa sus servicios y suplica le dé el oficio a su yerno y ayuda de costa para pagar sus deu-

110 AGS, CCl, 576. Carta venida en el galeón de 1620, del Tribunal de Lima para SM el 2 de mayo de 1620 .

III AGS, CCI, 576.

112 AGS, CCI, 576 .

113 AGS, CCI, 576.

114 AGS, CCI, 576.

115 AGS, CCI, 576.

$116 \mathrm{Ib}$ dem. 
das... Su objetivo queda bien claro: "ver casada una hija mía con un hidalgo vizcaíno que se dice Andrés de Zavala sujeto muy capaz y de calidad y partes ${ }^{177 " .}$ Este mismo año se le había concedido merced de 2000 ducados de ayuda de costa por los servicios librados en el Tribunal de Cruzada ${ }^{118}$. El subdelegado Velázquez, el 26 de junio de 1623, refiere los muchos servicios prestados por su persona, haciendo constar que sus méritos son mayores pues también lo había sido su celo "por ser cabeza del Tribunal"119. Aunque le reconoce los grandes alcances obtenidos y los pleitos levantados, el Arcediano expone que el beneficio gracias a su labor y a la del asesor. Insiste que, a pesar de doblarse la recaudación de los 150.000 ducados por predicación, más que al Contador se debe al Subdelegado "y a la mucha correspondencia que tenía con los maestros de doctrina que todos son sus discípulos", puesto que que, antes de llegar Don Gonzalo de la Maza, fue Velázquez quien había tomado asiento con Fco. Cano de Nebrija, tesorero de Lima, y Juan Antonio Báez, tesorero en Cuzco. No parece albergar resentimiento don Gonzalo de la Maza por el Subdelegado, ya que dos años después, el 30 de mayo de 1625, escribe al Rey para que premien al Dr. Velázquez ${ }^{120}$.

El 16 de marzo de 1627 encontramos la última, y todavía correctísima, firma del contador Don Gonzalo de la Maza' ${ }^{121}$.

\section{TESTAMENTO Y MUERTE}

En tales condiciones de agotamiento físico, con su enfermedad "de piedra" (cólico), "estando enfermo del cuerpo y sano de la voluntad, y en mi bueno seso juicio y entendimiento natural cual Dios Nuestro Señor fue servido de me dar", el 12 de septiembre de 1628 , dicta su testamento ${ }^{122}$. En el mismo deja traslucir su espiritualidad:

"y creyendo como firmemente creo en el misterio de la Santísima Trinidad, Padre, Hijo y Espíritu Santo, tres personas y un solo Dios verdadero y en todo aquello que tiene, cree y confiesa nuestra Santa Madre Iglesia Católica Romana y teniendo como tengo por mi Señora, guía y abogada en todos mis hechos, dichos y pensamientos a la gloriosa siempre Virgen María, Madre de Dios, Señora Nuestra, deseando poner mi ánima en carrera de salvación".

\footnotetext{
117 AGI, Indiferente, 2865.1. Madrid, 23 de marzo de 1622.

118 AGS, CCI, 576.

119 AGS, CCI, 576.

120 AGS, CCI, 576.

121 AGS, CCI, 576.

122 Archivo Histórico Riva-Agüero, Manuscrito 1-384. Trastado del Testamento hecho el 23 de julio de 1777 .
}

Missionalia Hispanica

Hispania Sacra 48 (1996) 
Nombra ejecutores del testamento a "Andrés de Zabala, mi yerno, y a DMU, mi querida y amada mujer", y como universales herederos a sus hijas y esposa, tanto del total los bienes personales como de la mitad de la herencia paterna en la villa de Ugarro (Santander), que compartió con su única hermana y sin hijos, Juana de la Maza.

Don Gonzalo de la Maza no llega a vivir más de un mes, puesto que el 10 de octubre emprendía su último y definitivo viaje, el de la eternidad. Era un 10 de octubre de 1628, según la "fe de muerte" levantada por el escribano real Gabriel de Rabandal. Se le amortajó con el hábito del Señor San Francisco. Figuran como testigos, el notario de Cruzada, Juan de Tamayo y Juan de Uros.

En el Memorial presentado al Consejo de Cruzada por DMU, viuda, para solicitar ayuda de costa, comenta los servicios prestados desde 1577 a 1600 y que nos sirve para sintetizar la actividad desarrollada. Entre otros hitos de su larga tarea se incluyen la revisión de cuentas de Nueva Granada en el que sacó desde 1574 más de 200.000 ducados de alcances y de los fraudes más de 75.000 ducados. En 1602-1603 visitó lo más importante, averiguando fraudes. El Marqués de Guadalcázar y el visitador Juan Gutiérrez Flores le dieron comisión para visitar el Tribunal de Contaduría Mayor donde quebrantó su salud y su vida con buenos servicios a la Real Hacienda doblando la suma. Rectitud y entereza de su vida como lo demuestra el hecho de dejar pobre a su mujer, la cual pide para su yerno A.Zabala, casado con su hija $D^{a}$ Andrea de la Maza, merced (se la dan) de 1.500 pesos de a 8 reales. De ellos han de pagar en concepto de media annata 24.400 maravedís en plata doble al tesorero de Cruza$\mathrm{da}^{123}$.

El 3 de marzo de 1636, por una real cédula se mandaba al Virrey librasen a DMU, 1.500 pesos como ayuda de costa, después de que hubiese pagado 75 pesos por la media annata de 20.400 pesos en plata. A los datos indicados anteriormente conviene anotar la de nuevo su laboriosidad'24 ("trabajó tanto que fue causa de su pérdida de salud y vida [...]") y transparencia ("entereza y rectitud con que procedió y gastos que hizo en largos viajes"), que llega a dejar "a su mujer tan pobre que quedó con 14.000 pesos de deuda ${ }^{125 "}$. A pesar de ello, si hacemos caso a los 413 pesos y 4 reales, que importó su entierro en agosto de 1628, sólo Juan de la Cueva superó en costo a nuestro contador,

${ }^{123}$ AGS, CCI, 572, Madrid 5.9.1631

124 Observamos como constante en todos los informes la competencia profesional y honestidad de vida. Uno de estos documentos puede consultarse en Archivo Histórico Nacional, Consejos, 7413. Madrid, 1629. G. de la Maza, informe visitador de ofrecer Misa. Desde 1600 en Perú, alcance de 200.000 ducados. Rectitud, limpieza y cristiandad.

125 AGS, CCI, 576. 
431, lo que demuestra que estaba a la cabeza la élite social y económica de la Lima del S.XVII'26.

Doña María, viuda del Contador, sobreviviría 16 años a su marido, dictando su testamento en Lima el 14 de mayo de 1644, ante el notario Diego Nieto Maldonado. Fue enterrada junto a su marido en la iglesia de los Jesuitas de Lima, al lado del Evangelio, en la capilla de san Ignacio, hasta que, con la construcción del Monasterio de Santa Rosa en su antigua casa, fueron trasladados sus restos a este lugar en el que reposan actualmente.

126 Libro de cuentar del Cabildo Catedralicio de Lima Archivo de ta Catedral, folio 2.

Missionalia Hispanica

Hispania Sacra 48 (1996) 